Revue d'histoire de l'Amérique française

REVUE D.HISTOIRE DE L'AMÉRIQUE FRANÇAISE

\title{
LACHAPELLE, Guy et Robert COMEAU, dir., Robert Bourassa : un bâtisseur tranquille (Québec, Les Presses de l'Université Laval, 2003), 406 p.
}

\section{Jacques Rouillard}

Volume 57, numéro 3, hiver 2004

URI : https://id.erudit.org/iderudit/009601ar

DOI : https://doi.org/10.7202/009601ar

Aller au sommaire du numéro

Éditeur(s)

Institut d'histoire de l'Amérique française

ISSN

0035-2357 (imprimé)

1492-1383 (numérique)

Découvrir la revue

Citer ce compte rendu

Rouillard, J. (2004). Compte rendu de [LACHAPELLE, Guy et Robert COMEAU, dir., Robert Bourassa : un bâtisseur tranquille (Québec, Les Presses de

l'Université Laval, 2003), 406 p.] Revue d'histoire de l'Amérique française, 57(3),

437-439. https://doi.org/10.7202/009601ar d'utilisation que vous pouvez consulter en ligne.

https://apropos.erudit.org/fr/usagers/politique-dutilisation/ 
LACHAPELLE, Guy et Robert COMEAU, dir., Robert Bourassa : un bâtisseur tranquille (Québec, Les Presses de l'Université Laval, 2003), 406 p.

Le volume fait suite au $14^{\mathrm{e}}$ colloque annuel sur les leaders du Québec contemporain tenu aux universités de Concordia et du Québec à Montréal en mars 2002. Destiné à tracer un portrait de Robert Bourassa, premier ministre en deux temps pour un total de près de 15 ans, et dans le but d'éclairer son apport à la vie politique du Québec, il rassemble 38 témoignages de journalistes, collègues en politique, fonctionnaires, universitaires et chefs de file de la société québécoise.

Comme on peut s'y attendre, ses proches au Conseil des ministres ou au sein du Parti libéral (une douzaine de témoignages) n'en finissent plus de souligner son pragmatisme, sa vive intelligence, son habileté, sa passion pour le Québec et même sa détermination. Pourtant, Bourassa a laissé généralement l'impression d'un premier ministre indécis, vacillant, mettant beaucoup de temps à prendre une décision à un moment de l'histoire du Québec où les crises graves n'arrêtent pas de se succéder (crise d'Octobre de 1970, grève du Front commun de 1972, crise linguistique en 1974, faillite de l'Accord de Meech, crise d'Oka en 1990). Mais pour ceux qui l'ont côtoyé de près, cette image n'est pas juste; ils le décrivent comme un homme tenace, ayant des opinions arrêtées et sachant fort bien où il veut s'orienter. C'est ce qui ressort même des deux textes consacrés à la crise d'Octobre par l'avocat Robert Demers et le criminologue Jean-Paul Brodeur qui réfutent l'interprétation d'un premier ministre paniqué dépendant de décisions prises à Ottawa. Pour ses collaborateurs, l'image d'indécision viendrait de son désir stratégique de parvenir à un large consensus avant d'arrêter une décision.

Cette interprétation n'est pas partagée par les journalistes Michel Vastel et Jean-François Lisée qui ne sont pas tendres envers le premier ministre. Lisée intitule son texte "Le marathonien immobile», acceptant bien de présenter Bourassa comme un homme déterminé, mais uniquement dans le but de conserver le pouvoir. Pour le reste, c'est à son avis un politicien sans convictions, cherchant constamment à reporter le moment de trancher. Je ne partage pas cette opinion sévère à l'endroit du premier ministre qu'on ne peut accuser de manquer d'orientation idéologique. Son supposé pragmatisme repose en fait sur une vision précise de l'avenir sociopolitique du Québec à partir de considérations économiques. Bien plus fier de sa formation d'économiste que de celle d'avocat, il partage essentiellement la vision des gens d'affaires qui subordonnent le social et le politique à l'économique. Plusieurs textes du volume font remarquer que le 
premier ministre accordait la priorité au développement économique et à la création d'emploi. Et ce développement devait s'effectuer par l'entreprise privée et en faisant appel aux investissements étrangers, deux orientations controversées à l'époque. Le texte de Michel Audet, sousministre de 1974 à 1977 et secrétaire général du Conseil exécutif de 1985 à 1987, est particulièrement instructif à cet égard. De ses comportements et de ses décisions, il déduit que «l'amélioration du niveau de vie de ses concitoyens était [aux yeux du premier ministre] l'une des rares valeurs, sinon la seule, [qui devait] constituer la priorité permanente de l'action politique dans les États modernes» (p. 92).

C'est à travers ce prisme qu'il faut comprendre son option fédéraliste et ses préoccupations sociales. Plusieurs textes font ressortir qu'il n'avait pas d'attachement émotif au Canada. Claude Ryan fait remarquer que sa défense du fédéralisme était "affaire de raison plutôt que de cœur» (p. 367). La structure fédérale lui apparaissait plus «rentable» pour le Québec à cause de sa dépendance géographique et économique envers le Canada. En contrepartie, l'indépendance politique du Québec représentait à ses yeux une option qui risquait d'entraver la croissance économique. Cette perspective utilitariste se retrouve aussi dans ses choix politiques touchant le social et le culturel (lois linguistiques) où son bilan n'est pas très reluisant et son attentisme assez évident. Certains de ses leitmotiv relatés par les auteurs des textes reflètent cette perspective : «Pas de progrès social et de sécurité culturelle, sans croissance économique» (p. 79); «Il faut créer la richesse avant de la redistribuer» (p. 92); "On ne peut pas bâtir le socialisme sur la pauvreté» (p. 265). À l'époque, le Parti québécois avait une tout autre représentation des rapports entre le social et l'économique : non pas que les considérations économiques soient absentes de ses choix, mais il ne lui subordonnait pas aussi étroitement les autres aspects de la vie publique.

Il nous semble que la création du Parti québécois en 1968 avec une orientation social-démocrate a eu pour effet de pousser le Parti libéral davantage à droite, le rapprochant des milieux d'affaires. Ces derniers, qui craignent aussi la montée du Parti québécois, fondent au même moment une institution unique en Amérique du Nord, le Conseil du patronat du Québec, chargé de défendre leurs intérêts. La philosophie qui anime le jeune Robert Bourassa quand il devient chef du Parti libéral et premier ministre en 1970, avec le slogan de créer 100000 emplois, correspond très bien aux attentes des gens d'affaires. Son «économisme» ne se dément pas par la suite, notamment après son élection en 1985 alors que son administration adopte un discours nettement néolibéral prônant la déréglementation, la privation et 
un allégement du rôle de l'État. Sur ces trois thèmes, il accepte la création de trois comités d'études formés majoritairement de représentants des milieux d'affaires qui proposent un vaste programme de gouvernement. Même si le premier ministre prend une certaine distance à l'égard des recommandations des comités, il n'en reste pas moins qu'elles influencent fortement ses politiques. Il est malheureux que les textes du volume n'insistent pas suffisamment sur les rapports de ces trois comités dont la philosophie continue de nos jours à inspirer le gouvernement libéral.

Le volume représente certainement un bilan précieux pour comprendre à la fois la personnalité de Robert Bourassa et les décisions de son gouvernement. C'est d'autant plus utile que ce premier ministre a dirigé les destinées du Québec pendant une longue période. On doit en remercier les organisateurs du colloque qui ont fait œuvre utile notamment en amenant ses proches en politique à ramasser leurs souvenirs, ce qu'ils n'auraient jamais fait si on ne les avait sollicités. Même s'ils sont élogieux, leurs témoignages seront précieux pour les historiens de demain qui se pencheront sur cette période mouvementée de l'histoire du Québec. L’ensemble des textes du volume ne représente néanmoins qu'une première ébauche du personnage qui ne saurait remplacer un travail en profondeur à partir des archives.

JACQUES ROUILLARD

Département d'histoire

Université de Montréal

LAURIN, Serge, Sainte-Agathe-des-Monts. Un siècle et demi d'histoire (Québec, Les Presses de I'Université Laval, 2002), 336 p.

Réalisée par l'auteur de l'histoire régionale des Laurentides publiées aux Presses de l'IQRC en 1989, cette monographie d'histoire locale retrace les principales transformations d'une petite ville laurentienne depuis sa fondation en 1849 jusqu'à nos jours. Il s'agit d'un ouvrage commandé par le Comité du patrimoine de Sainte-Agathe-des-Monts dans le cadre du $150^{\mathrm{e}}$ anniversaire de la fondation de la municipalité. La directive du commanditaire était claire : la monographie historique doit s'inscrire «en rupture avec les ouvrages généralement produits dans ces cas, à savoir la forme d'album qui se résume à la rédaction de quelques textes anecdotiques entrelardés de photos d'époque et, surtout, mettant l'accent sur la liste des curés, des premiers colons ou celle de quelques personnages célèbres par leurs exploits ou leur originalité» (p. 1). L'auteur a su relever 